\title{
Sombras do Araguaia na minha vida
}

\section{Guiomar de Grammont}

Eu fazia a graduação em História, em Mariana, quando encontrei num sebo uma revista sobre a Guerrilha do Araguaia, publicada em 1978, em uma parceria entre o historiador Sérgio Buarque de Holanda, o jornalista Palmério Dória, e o fotógrafo Vincent Carelli ${ }^{1}$. Ousada e interessante, a revista falava da guerrilha a partir de quatro perspectivas: a dos guerrilheiros, em que o entrevistado era José Genoíno², ainda completamente desconhecido do público; a dos militares, com o depoimento de Jarbas Passarinho ${ }^{3}$ e a dos índios, os quais descreviam com onomatopeias a invasão dos céus por helicópteros militares. No momento em que descobri a revista, nos anos oitenta, a guerrilha, que tinha acontecido em datas imprecisas entre 1969 e 1976, era ainda cercada por um muro de censura e silêncio que os militares haviam imposto sobre esse episódio, um dos mais trágicos da história do Brasil. Cerca de oitenta guerrilheiros e camponeses participaram do conflito, que não deixou mais do que vinte sobreviventes.

Li, fascinada, o relato sobre a perseguição aos guerrilheiros na mata e sobre suas estratégias e esconderijos para sobreviver na floresta. Eu tinha uma convicção íntima, sem nenhuma comprovação, de que a morte de meu pai teria algo a ver com a guerrilha, movimento que aconteceu em áreas que ele visitara algumas vezes no mesmo período, em suas explorações geológicas. Meu pai faleceu a 29 de novembro de 1975, em Goiânia, em circunstâncias semelhantes às da morte do jornalista Vladimir Herzog, que ocorreu um mês antes, no dia 25 de outubro: um assassinato que fizeram parecer suicídio.

A Guerrilha do Araguaia me obcecou a tal ponto que, em 2015, depois de muitas pesquisas sobre o evento, lancei o romance Palavras Cruzadas, que conta a história ficcional de Sofia, a jornalista que procura seu irmão Leonardo, guerrilheiro desaparecido no Araguaia. A escrita desse livro, que tomou cerca de cinco anos da minha vida, foi quase medicinal. Atribuía minhas dificuldades para escrever e publicar à impossibilidade de lidar

\footnotetext{
${ }^{1}$ Coleção História Imediata, volume 1: A Guerrilha do Araguaia. São Paulo: Alfa-ômega, 1978.

${ }^{2}$ José Genoino Neto, político brasileiro, ex-presidente do Partido dos Trabalhadores, ex-deputado federal pelo estado de São Paulo e ex-guerrilheiro.

${ }^{3}$ Militar e político brasileiro. Foi governador do Estado do Pará, na época da ditadura foi ministro do trabalho, da educação, da previdência social e da justiça, além de presidente do Senado Federal.
} 
com a morte do meu pai, que ficara tão mal resolvida em minha vida. Contar a saga de Sofia em busca da verdade teve um efeito catártico.

Centrado na discussão sobre a Anistia e o Esquecimento, em Paul Ricoeur, e sobre a Narrativa e o Perdão, em Hannah Arendt, meu livro parece, tristemente, mais atual agora, do que no momento em que foi lançado. Marcos, um amigo filósofo da minha protagonista, lhe fala sobre a Anistia em Paul Ricoeur, relacionando o conceito à dor que Sofia e sua mãe vivenciam desde o desaparecimento do filho e irmão na Guerrilha do Araguaia. Para Ricoeur, a anistia cicatriza à força, é o esquecimento imposto, induz a uma espécie de amnésia coletiva, que impede uma revisão do passado. Para o francês, ao contrário do que parece, a anistia impede o perdão. Para haver perdão, é preciso soltar todo o ressentimento. Só a narrativa e a memória, ou seja, a revisão do passado, permitiriam o perdão. Seria preciso recontar a história com os olhos do presente, para exorcizar a dor.

A reflexão de Marcos sobre Paul Ricoeur o leva a falar também de Hannah Arendt, a pensadora judia de origem alemã, que dedicou grande parte da sua vida intelectual à tentativa de compreender o holocausto. Para ela, somente o entendimento tornaria possível uma reconciliação com o mundo, para que se possa continuar vivendo, depois do horror. Só o perdão pode permitir começar de novo, pois ele liberta tanto quem perdoa quanto quem é perdoado, do peso do passado. Para a autora, o perdão é um conceito que estaria na base de todas as formas de anistia, comutação ou supressão de pena.

No romance, Sofia lembra que, imersos no sofrimento pelo desaparecimento do filho, seus pais não se sentiram melhor em 1979, quando foi promulgada a Lei da Anistia no Brasil. Pelo contrário, ficaram ainda mais ansiosos, como se esperassem uma revelação. Era preciso alguma forma de desfecho para lhes dar algum alívio, o que não aconteceu.

Para resolver essa angústia, o personagem Marcos evoca que seria preciso abrir os arquivos, dar luz a tudo que aconteceu. Revelar como foram mortos os desaparecidos e, se possível, onde estão seus corpos. Rememorar, enfim. Mas isso significaria também apontar os responsáveis. E isso não aconteceu no Brasil. O pressuposto, sob a Lei da Anistia promulgada aqui, foi o de que não haveria diferença entre os torturadores e os guerrilheiros. Ambos cometeram atrocidades contra os direitos humanos e ambos foram igualmente anistiados. Tal como preconizava Hannah Arendt, no Brasil, a Anistia impediu uma Narrativa sobre os acontecimentos, catharse essencial para que pudéssemos recomeçar em outras bases, sem repetir os erros do passado.

Na orelha que apresenta meu livro, o jornalista e ensaísta Laurentino Gomes escreveu: 
"Palavras-Cruzadas", romance da professora e escritora Guiomar de Grammont, é um dos livros mais bonitos - e bem escritos - que li ultimamente, poderosa metáfora do Brasil de hoje. (...) É uma estória permeada de incertezas e perguntas, com respostas incompletas e insatisfatórias. Um clima de tragédia paira sobre os personagens e acontecimentos. O que, de fato, aconteceu? Quem são essas pessoas? Que segredos estão escondidos em suas memórias e nas gavetas que guardam documentos misteriosos?

Laurentino não imaginava que sua afirmação se mostraria ainda mais precisa, poucos anos depois: mais do que nunca, meu livro se mostra como uma "poderosa metáfora do Brasil de hoje". O jornalista deu como exemplo as frases que abrem o romance - "Parece um sonho agora, o mato cresce nas picadas abertas. As feridas tornaram-se cicatrizes, irão desaparecer, pouco a pouco. Como os nomes. Vão sendo esquecidos, pouco a pouco, com o que não queremos lembrar". Laurentino afirma:

(...) essas mesmas frases poderiam ser usadas para descrever o Brasil de hoje, às voltas com seus tortuosos desvios de memória. Há trinta anos os brasileiros deixaram para trás o último de seus muitos períodos de ditadura para enfrentar um desafio inédito na sua história: a construção do futuro pela democracia representativa. Ao contrário dos países vizinhos, no entanto, o Brasil tem demonstrado enorme dificuldade em esclarecer os casos de torturas, prisões, assassinatos e outros episódios obscuros da época do regime militar. Há inúmeras "comissões da verdade" em funcionamento no país, mas o clima de má vontade em relação às investigações, especialmente no meio militar, é evidente.

Eu não tinha consciência, no momento da publicação, do quanto meu livro estava sendo profético. Daria tudo para não vivenciar o que passamos em seguida, no Brasil. $\mathrm{O}$ pesadelo em que mergulhamos em 2018 parecia previsto nas falas dos meus personagens. Essa dificuldade de lidar com o passado recente originou os problemas que temos na atualidade para estabelecer uma «democracia representativa», como a nomeia Laurentino. Através das minhas personagens, eu estava dando forma a um silêncio que pairava no ar, silêncio que repercutia o ressentimento dos militares que, em sua sede de poder, julgavam que tinham sido solapados pela abertura política e avalizaram a ascensão da extrema-direita ao poder em 2019.

Laurentino evidencia o quanto esse ressentimento tem a ver com a inexistência de uma narrativa sobre nosso passado recente e a falta de um julgamento dos responsáveis ou, 
no mínimo, um movimento de abertura dos arquivos, para fazer falarem os mortos e os desaparecidos. A Comissão da Verdade foi um passo importante nessa direção, mas não houve uma divulgação expressiva dos seus resultados. Isso poderia ter tornado a sociedade brasileira mais refratária à reescrita da história empreendida por aqueles que tomaram o governo no Brasil, à partir das eleições de 2018. A resenha que Laurentino escreveu, em 2015, parece referir-se ao que veio a acontecer pouco depois:

São palavras que ecoam fortemente no Brasil de hoje - um país que, por medo das verdades escondidas no passado, tenta cicatrizar à força feridas ainda recentes, sem se dar ao trabalho de entender o que as provocou e de que matéria são constituídas. O que faz do romance de Guiomar de Grammont não apenas uma bela peça literária, mas também um libelo político a respeito do qual todos os brasileiros são chamados a meditar.

O que chamamos "memória individual" não passa, segundo Halbwachs, de um ponto de vista da "memória coletiva" e todo evento narrado na verdade é uma alegoria do passado. ${ }^{4}$

Talvez, o pressentimento sobre o que se passaria habitasse em mim desde muito antes. Essas forças contraditórias se digladiavam no inconsciente coletivo de muitos brasileiros. De qualquer forma, não me senti mais preparada para o que aconteceria em seguida. As consequências do traumático Golpe de 2016 me atingiram, como a muitos outros intelectuais e artistas de esquerda, com a força de uma avalanche.

Muitas resenhas importantes foram realizadas sobre meu romance Palavras Cruzadas e eu já tinha perdido as esperanças de que saísse alguma coisa no jornal O Globo. No dia 29 de agosto de 2015, tive a boa surpresa de abrir o jornal e encontrar a belíssima resenha intitulada «Memória e Perdão», de José Castello, um dos ensaístas e escritores que mais conhece a literatura brasileira. Castello percebeu minha personagem como uma Antígona contemporânea e compreendeu que a chave do romance é a memória, contra o esquecimento promovido pela anistia.

A referência a Antígona já se encontra na epígrafe que dei ao livro, emprestada da peça de Sófocles: "Seu irmão jazia insepulto; ela não quis que ele fosse espedaçado pelos cães famintos ou pelas aves carniceiras". Ao fazer esse paralelo, eu quis enfatizar a presença do

\footnotetext{
${ }^{4}$ Halbwachs, M. A Memória coletiva. Trad. de Laurent Léon Schaffter. São Paulo, Vértice/Revista dos Tribunais, 1990. Tradução de: La mémoire collective.
} 
ausente, a falta de um corpo para enterrar, enfim, a angústia do desaparecimento de uma pessoa querida, vivenciada por tantas famílias do Brasil e de outros países da América Latina.

Ambas as heroínas, do meu romance e da peça de Sófocles, segundo Castello, lidam com uma das mais antigas dificuldades do ser humano: «a memória». O ensaísta completa: «Também Antígona lutou para que o corpo de seu irmão não ficasse insepulto. Uma luta para chegar ao verdadeiro fim. Para chegar à verdade.» (...) «Como Antígona, também Sofia luta pelo direito à memória. Não quer ressuscitar um morto, quer - nem que seja em seu coração - enterrá-lo. Castello acrescenta: «Não só a memória pode nos salvar: a fantasia (a ficção) também. Ao fim de tudo, o que salva mesmo é a palavra - é poder nomear um destino. É o nome». Como prova, o resenhista cita a passagem do romance em que o guerrilheiro do misterioso diário que cai nas mãos de Sofia escreve: "Eu gritava o seu nome, para tentar aliviar a minha angústia". Para Castello, Sofia é «uma rigorosa exegeta» que sabe que só a decifração do manuscrito que tem em mãos poderá conduzi-la à verdade, à descoberta do que aconteceu com seu irmão. E conclui, com uma interpretação sobre o título do romance:

É nessa encruzilhada, entre recordar e esquecer, que Sofia se debate. Não são apenas destinos cruzados: são palavras cruzadas que a empurram, mas, ao mesmo tempo, a devoram. O romance de Guiomar trata, no fim das contas, da memória humana, que parece inacessível, mas é insubstituível.

Para construir o relato do guerrilheiro perdido na mata, mencionado por Castello, cruzei alguns relatórios de guerrilheiros que estiveram no Araguaia. Esses textos me chegaram por vias curiosas, o que mostra o quanto o evento era ainda cercado de silêncio quando comecei a escrever meu livro, por volta de 2010. O primeiro, que compõe a maior parte da narrativa que criei, é o do guerrilheiro Glênio Sá. Glênio Fernandes de Sá se perdeu do grupo e foi capturado logo no início da guerrilha, assim como José Genoíno, que entrevistei na Câmara dos Deputados, em Brasília. Glênio faleceu em um acidente de carro, em 1990, quando preparava sua candidatura para o Congresso. O relato de suas incríveis experiências, enquanto esteve perdido na floresta amazônica, foi publicado numa tiragem muito limitada, mais para militantes do partido ${ }^{5}$. Alicia Duarte Penna, amiga poeta, de Belo Horizonte, tinha acabado de perder seus pais. Em uma experiência de revivescimento doloroso da memória comparável à da minha protagonista Sofia, Alicia arrumou a casa em

${ }^{5}$ Sá, Glênio. Relato de um guerrilheiro. Belo Horizonte: Anita Garibaldi Editora, 2004. 
que eles tinham vivido para vendê-la. Minha amiga encontrou esse livro ao arrumar as coisas do pai. Trouxe a pequena brochura e me entregou, emocionada, sem saber se ela me serviria. Foi um presente precioso.

O outro relatório que utilizei, de um dos chefes da Guerrilha, Maurício Grabois, me chegou através do jornalista e escritor Lucas Figueiredo, que o obtivera de uma fonte secreta. Muito inspiradora, para mim, a leitura do excelente ensaio de Figueiredo, «Olho por olho: os livros secretos da ditadura» ${ }^{6}$, sobre o impressionante esforço coordenado e secreto, para construção dos relatórios publicados no «Brasil: Nunca mais!». Lucas foi o primeiro a falar também, sobre o Orvil, ou livro ao contrário, espécie de resposta dos militares às denúncias publicadas pela esquerda naquela ocasião. O Orvil foi urdido secretamente por alguns anos e, no momento em que Lônidas Pires Gonçalves era ministro do exército, quiseram publicálo, o que foi vetado por José Sarney, então presidente. Esse livro, que apresenta os militares como heróis que lutaram contra uma suposta ameaça «comunista», deu origem à guerra cultural bolsonarista da qual somos vítimas na atualidade e que consiste numa difusão maciça de inverdades que subvertem a história.

Em 2013, minha amiga Lucilia Neves, poeta e importante historiadora do Brasil República, ao saber que eu fazia um romance sobre a Guerrilha do Araguaia e Cléria Botelho da Costa, ambas professoras da UNB, me convidaram para participar da banca de doutorado que julgaria a tese do jornalista Hugo Studart, intitulada «Em algum lugar das selvas amazônicas: as memórias dos guerrilheiros do Araguaia (1966-1974).» ${ }^{7}$ Eu li os dois grossos volumes em um par de dias, horrorizada com o destino dos guerrilheiros aprisionados no período em que o General Emílio Garrastazu Médici, que governou o Brasil de outubro de 1969 a março de 1974, ordenou a sumária execução de todos os prisioneiros. A leitura da tese foi fundamental, pois me trouxe elementos sobre a vida das mulheres na Guerrilha que contribuíram muito para a verossimilhança do romance.

Apesar de algumas referências a figuras centrais na Guerrilha, optei pela ficção ao criar meus protagonistas, pois eles são uma colagem de elementos e experiências de diversas pessoas, inclusive eu mesma. A angústia vivida por Sofia e sua mãe tem muito da dor que minha mãe, eu e meus irmãos vivenciamos, quando meu pai morreu. Quando publiquei o romance, minha mãe, que hoje costuma preferir as novelas aos livros, sentou-se numa cadeira em frente à janela e o leu inteiro, em uma tarde. Quando a noite caiu, ela o terminou,

\footnotetext{
${ }^{6}$ Rio de Janeiro: Record, 2009.

${ }^{7}$ Corrêa, Carlos Hugo Studart. Em algum lugar das selvas amazônicas: as memórias dos guerrilheiros do Araguaia (1966-1974). 2013. 619 f., il. Tese (Doutorado em História) - Universidade de Brasília, Brasília, 2013.
} 
chorando. De certa forma, reconheceu no livro os sentimentos que experimentamos quando nosso pai foi violentamente arrancado da nossa existência. Ela tinha seis filhos pequenos, eu, a mais velha, mal completara doze anos.

Um bom romance, porém, é o resultado de muitas re-escrituras. O escritor precisa saber ouvir críticas sem levá-las para o plano pessoal e deve ter suficiente desprendimento para recomeçar e cortar partes que muitas vezes já não lhe parecem imprescindíveis, de tanto relê-las. Eu cortei cerca de 100 páginas do romance que havia enviado inicialmente à editora Vivian Wyler, da Rocco, surpreendendo-a, e não me arrependo. Para revisar os originais que já tinha entregado à Rocco, contei com as preciosas leituras da excelente editora Rosana Caiado e de outros amigos, como Lucas Figueiredo e sobretudo Paulo Markun, jornalista que vivenciou os eventos da ditadura nos anos 70 e escreveu sobre eles. Markun fez observações implacáveis, porém, sempre pertinentes.

Em 2012 e 2013, com anuência do meu departamento na Universidade Federal de Ouro Preto, atuei como editora executiva de ficção nacional na Record, uma das casas editoriais de maior reputação do Brasil. Me dedicara com extrema atenção a atender, na medida do possível, as solicitações dos diversos autores do rico catálogo da editora. Depois de dois anos, chegara o momento de pensar em dar continuidade à minha obra, então, deixei a Record disposta a voltar às minhas atividades como escritora.

A experiência como editora, de qualquer forma, foi fundamental para a construção do Palavras cruzadas. Utilizei recursos folhetinescos para estimular o leitor a levar a leitura até o fim com interesse crescente, em um «em delicado ritmo de suspense», como definiu Castello. Isso pode ter tornado esse romance menos potente do que os contos que publiquei antes, mas, sem dúvida contribuiu para torná-lo lido por pessoas das mais variadas idades e formações. Fico especialmente gratificada quando as pessoas me contam que começam a lê-lo e não conseguem parar enquanto não o terminam.

Em 2017, a professora Eurídice Figueiredo dedicou várias páginas ao meu romance em sua obra excelente: A literatura como arquivo da ditadura brasileira ${ }^{8}$, dando início a uma série de trabalhos acadêmicos sobre o tema. Em 2020, as professoras Rita Olivieri-Godet e Mireille Garcia, da Universidade de Rennes 2, publicaram o interessante dossiê com o tema "Literatura e ditadura", na Revista "Estudos de Literatura Brasileira Contemporânea" n 60, da Universidade de Brasília, em 2020․ Nesse dossiê, a professora Leonor Lourenço de

\footnotetext{
${ }^{8}$ Figueiredo, Eurídice. Rio de Janeiro: 7Letras, 2017.

9 Olivieri-Godet, R., \& Garcia, M. Apresentação: literatura e ditadura. Estudos de Literatura Brasileira Contemporânea, (60), 1-5. 2020. https://doi.org/10.1590/2316-4018600
} 
Abreu, da Université Catholique de Louvain publicou um artigo sobre meu livro, abrangendo todas as polêmicas que o cercaram desde sua publicação. Em uma análise complexa, sem deixar de fazer uma crítica construtiva, muito enriquecedora para mim, a professora sintetizou com perfeição os propósitos do romance: «O percurso de resiliência que subjaz à construção narrativa de Grammont indica uma postura ética embasada na ideologia da tolerância.» A autora compreende «resiliência» no plano social ou coletivo como «a faculdade de que dispõem certos indivíduos ou comunidades para fazerem face a episódios dolorosos -traumas históricos, massacres, genocídios - sem abismarem-se na angústia da desagregação, melancolia e morte, e se reconstruírem através de novos projetos, numa dinâmica de reconciliação com a ideia mesma de existência ». ${ }^{10}$

Em 2015, a editora Rocco alugou uma casa em Paraty, durante a FLIP, na qual organizou, pela primeira vez, uma programação intensa com seus autores. A editora dedicou especial atenção ao meu livro: coube-me participar de uma mesa com Frei Betto, autor e amigo que publicou diversas obras sobre as experiências que viveu como militante contra a ditadura, inclusive na prisão. Assistiram ao debate na casa lotada grandes figuras, como o escritor Leonardo Padura, que estava participando da FLIP nessa ocasião e era amigo de Frei Betto, além de jornalistas, editores, escritores e público em geral. Em sua fala, Frei Betto fez uma observação que nunca esqueci: - "A Guiomar fala da guerrilha, mas ela não doura a pílula. Ela não deixa de mencionar os erros que nosso lado cometeu."

De fato, evitei apresentar os guerrilheiros como heróis, não deixando de ressaltar a hierarquia autoritária dos chefes para-militares da Guerrilha. Procurei ressaltar no livro minha postura pacifista, radicalmente contra as armas, seja qual for a ideologia que esteja empunhando-as. Por essa razão, o romance Palavras Cruzadas não deixou de provocar polêmica, por apresentar uma imagem nuançada dos terríveis eventos vividos no Araguaia. Como colocou Leonor Lourenço de Abreu: «O questionamento da perspectiva revolucionária - o dogmatismo apaixonado -, que o romance tematiza, imprime à obra um caráter crítico». A autora completa:

O romance foge, porém, ao binarismo culpado/inocente; antes negocia um meio termo - a terceira margem - entre vitimismo e liberdade assumida, buscando explorar os meandros recônditos do recalcado num processo que vai da dilaceração psíquica à reabilitação ontológica, nos antípodas de qualquer lógica dicotômica. ${ }^{11}$

\footnotetext{
${ }^{10}$ Abreu, Leonor Lourenço de. Da ocultação à memória difratada: a escrita da resiliência em Palavras cruzadas, de Guiomar de Grammont. Estudos de Literatura Brasileira Contemporânea, (60), 1-5. 2020.

${ }^{11}$ Abreu, Leonor Lourenço de (2020). Da ocultação à memória difratada: a escrita da resiliência em Palavras cruzadas, de Guiomar de Grammont. Estudos de Literatura Brasileira Contemporânea, (60), 1-5. 2020. p. 4
} 
A representação que fiz dos militares no romance, como pessoas comuns, chegou a induzir interpretações que atribuíam ao meu livro o contrário do que ele queria dizer, por parte dos que julgam os eventos da ditadura com uma miopia maniqueísta. Ao criar a figura do militar paralítico, que já não pode falar, eu buscava uma metáfora da censura e do silenciamento imposto sobre esses trágicos eventos. Mais uma vez, Leonor Lourenço de Abreu compreendeu o livro melhor do que eu mesma o faria:

Em sua formulação narrativa, Palavras cruzadas assume uma postura ética que se aproxima da perspectiva de Hannah Arendt e de testemunhas diretas do holocausto nazista, como Primo Levi: "Os monstros existem, mas eles são muito pouco numerosos para serem realmente perigosos; os mais perigosos são os homens comuns" (Todorov, 1994, p. 133, tradução da autora do artigo ${ }^{12}$ ). O "mal extremo", propiciado por seres prontos a obedecer e a agir sem questionar, em vez de ser um mal radical, isto é inumano, acaba sendo, paradoxalmente, banal, no quadro de sobredeterminações de ordem política e social, que subsumem as motivações psicológicas e individuais -sem exonerarem o indivíduo da sua responsabilidade legal e moral. ${ }^{13}$

Meu livro não deixa de rejeitar a forma de anistia realizada no Brasil, sempre defendi a responsabilização dos militares pelos crimes cometidos durante a ditadura. Como apontou o professor Roberto Vechi, professor de literatura portuguesa e brasileira da Universidade de Bolonha, «Palavras cruzadas não é, certamente, um livro 'revisionista' ou 'negacionista' (...) sua escrita oximorística revela os mistérios insondáveis da alma humana e contribui para restaurar 'a voz das vítimas silenciadas dos massacres' ${ }^{14}$

Ainda nos anos 90, Davi Arrigucci falou da minha obra para sua amiga Anne-Marie Métailié, que criara na França uma editora com esse nome - a Métailié - especializada sobretudo em livros brasileiros traduzidos para o francês. Muitos anos depois, eu a conheci, em São Paulo, em um evento sobre literatura no Itaú cultural e, depois, nos reencontramos algumas vezes, na França e no Brasil. Tomei coragem e mandei para Anne-Marie meu livro numa versão anterior, cerca de um ano antes de publicá-lo. Ela me enviou observações bastante pertinentes, e eu as incorporei ao livro, como fiz com outras, de amigos e familiares.

\footnotetext{
12 Todorov, Tzvetan (1994). Face à l'extrême. Paris: Seuil. APUD Abreu, Leonor Lourenço de. p.7

13 Abreu, Leonor Lourenço de. p.7

14 Vecchi, Roberto. O passado subtraído da desaparição forçada: Araguaia como palimpsesto. Estudos de Literatura Brasileira Contemporânea, Brasília, n. 43, p. 133-139, jan./jun, 2014.
} 
Quando finalmente leu o romance publicado, Anne-Marie, me escreveu uma mensagem curta, que recebi com regozijo: «Guiomar, si ce n'est pas trop tard pour me déclarer, je veux publier ton livre.» Fiquei muito feliz porque sei que a Métailié conquistou a boa reputação que tem na França por causa do rigor na escolha de ótimos livros para o seu catálogo. Anne-Marie escolheu uma capa esplêndida para a edição francesa, publicada em 2017, com a imagem de uma vegetação densa em cor cinza. A editora percebeu muito bem que a floresta amazônica é a protagonista do romance, e criou, como costuma fazer com os livros que publica, um novo título para a edição francesa: «Les ombres de l'Araguaia» ou «As sombras do Araguaia», evocando, «os espectros alimentados por segredos do passado, que vêm atormentar os indivíduos e os grupos sociais» (...) quando «os mortos sem sepultura voltam para assombrar os vivos envolvendo-os na espiral do desastre, hipotecando o seu futuro». ${ }^{15} \mathrm{O}$ livro chamou atenção na França também devido à tradução bem cuidada, por Danielle Schramm, com um glossário dos termos que meus personagens utilizam, dos povos que habitam a floresta amazônica.

Em outubro de 2019, em Paris, a competente diretora brasileira Marcia de Castro ${ }^{16}$, realizou a leitura dramática de excertos do «Les ombres de l'Araguaia», na Mairie do Ilème, para uma plateia lotada. A diretora mobilizou mais de dez atores, em sua maioria, antigos colegas seus da Ancienne Comédie Française. O resultado, com recursos cênicos simples, mas sofisticados, foi belíssimo. O público se emocionou até as lágrimas quando a jovem Anaïs Maurette cantou a música "Caminhando e cantando», de Geraldo Vandré, acompanhada pelos atores e pelas pessoas da plateia.
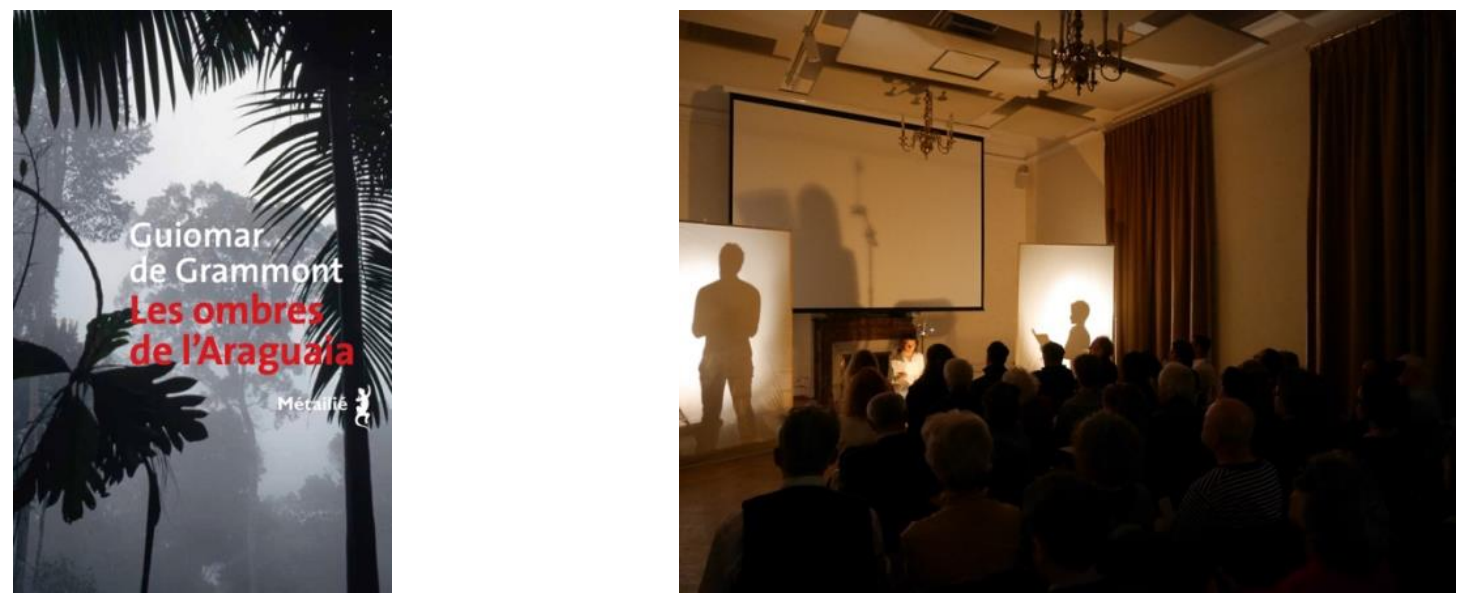

\footnotetext{
${ }^{15}$ Abreu, Leonor Lourenço de. Da ocultação à memória difratada: a escrita da resiliência em Palavras cruzadas, de Guiomar de Grammont. Estudos de Literatura Brasileira Contemporânea, (60), 1-5. 2020. p. 4.

${ }^{16}$ A leitura foi dirigida por Márcia de Castro, que também atuou como narradora, junto com os atores: Elodie Chanut, Christine Laurent, Jean-Noël Dahan, Adrien Melin, Valentin de Carbonnières, Jean François Torre, Anaïs Maurette de Castro, Patricia Varnay, Marianne Wolfsohn.
} 

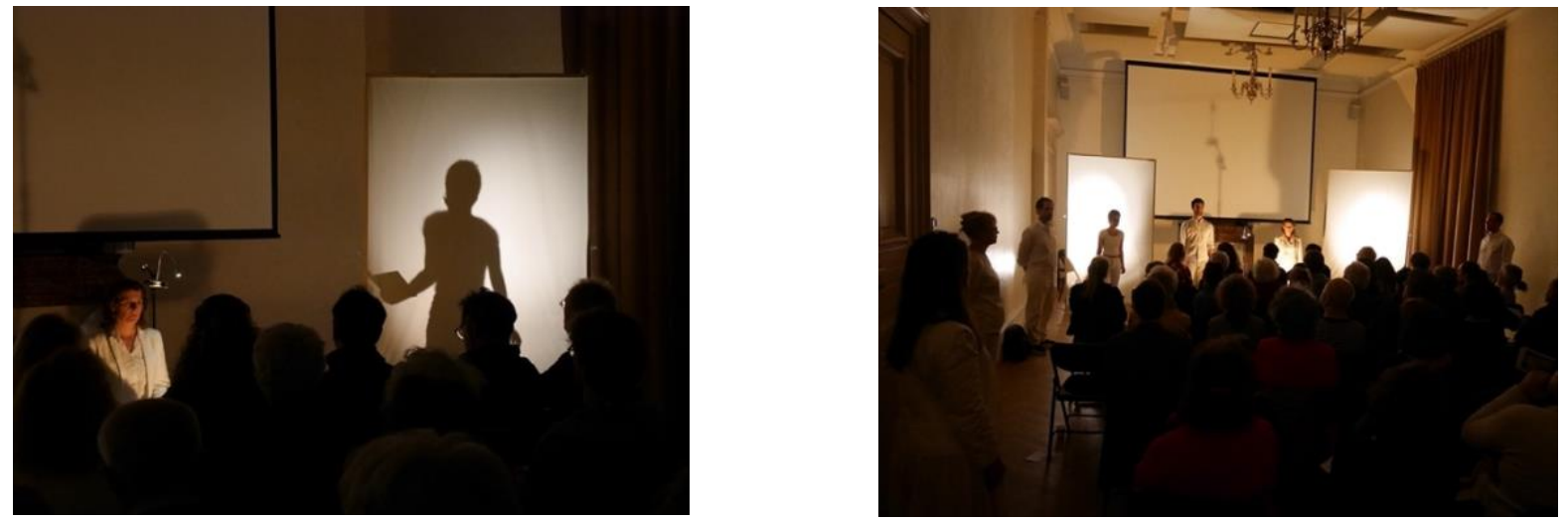

\section{Referências bibliográficas}

Abreu, Leonor Lourenço de. (2020) Da ocultação à memória difratada: a escrita da resiliência em Palavras cruzadas, de Guiomar de Grammont. Estudos de Literatura Brasileira Contemporânea, (60), 1-5.. https://periodicos.unb.br/index.php/estudos/issue/view/1995

Castello, José. (2015) Memória e Perdão. O Globo, Rio de Janeiro, 29 ago. https://blogs.oglobo.globo.com/jose-castello/post/memoria-e-perdao.html

Carelli, Vincent; Holanda, Sergio Buarque de; Dória, Palmério. (1978) Coleção História Imediata, volume 1: A Guerrilha do Araguaia. São Paulo: Alfa-ômega.

Corrêa, Carlos Hugo Studart. (2013) Em algum lugar das selvas amazônicas: as memórias dos guerrilheiros do Araguaia (1966-1974). 619 f., il. Tese (Doutorado em História) - Universidade de Brasília, Brasília.

Figueiredo, Eurídice. (2017) A literatura como arquivo da ditadura brasileira. Rio de Janeiro: 7Letras.

Figueiredo, Lucas. (2009) Olho por olho: os livros secretos da ditadura. Rio de Janeiro: Record.

Gomes, Laurentino. In: Grammont, Guiomar. (2015) Palavras cruzadas. Rio de Janeiro: Rocco.

Grammont, Guiomar. (2015) Palavras cruzadas. Rio de Janeiro: Rocco. (2017) Les ombres de l'Araguaia. Traduzido por Danielle Schramm. Paris: Métailié.

Olivieri-Godet, R., \& Garcia, M. (2020) Apresentação: literatura e ditadura. Estudos de Literatura Brasileira Contemporânea, (60), 1-5. https://periodicos.unb.br/index.php/estudos/issue/view/1995

Halbwachs, M. A. (1990) Memória coletiva. Trad. de Laurent Léon Schaffter. São Paulo, Vértice/Revista dos Tribunais. Tradução de: La mémoire collective.

Sá, Glênio. (2004) Relato de um guerrilheiro. Belo Horizonte: Anita Garibaldi Editora.

Vecchi, Roberto. (2014) O passado subtraído da desaparição forçada: Araguaia como palimpsesto. Estudos de Literatura Brasileira Contemporânea, Brasília, n. 43, p. 133-139, jan./jun. 